\section{Longitudinal OUtcome of Young Adults Who Participated in a Psychiatric Vocational Rehabilitation Program}

\author{
Marsha Langer ElLISON, \\ Karen Sue Danley, \\ Clifford Bromberg, \\ $\&$ Victoria Palmer-Erbs
}

THIS STUDY WAS FUNDED BY THE NATIONAL INSTITUTE FOR DISABILITY AND REHABILITATION RESEARCH, U.S. DEPARTMENT OF EDUCATION GRANT NO. H133G20070-93.

\section{MARSHA LANGER ELLISON, PHD, IS A CENTER FOR PSYCHIATRIC REHABILITATION, BOSTON UNIVERSITY AND AN ADJUNCT ASSISTANT HEALTH AND REHABILITATION \\ THE LATE KAREN S. DANLEY, PHD, WAS HE DIRECTOR OF THE DEVELOPMENT DIVISION AT THE CENTER FOR BOSTON UNIVERSITY \\ CLIFFORD BROMBERG, PHD, IS A STAFF PSYCHOLOGIST AT BRADLEY HOSPITAL IN PROVIDENCE RHODE ISLAND, WHERE HE PROVIDES OUTPATIENT ERVICES AND EVALUATIONS FOR AND FAMILIES}

VICTORIA K. PALMER-ERBS, PHD, RN, CS, S A CERTIFIED, PSYCHIATRIC CLINICAL NURSE SPECIALIST AND MEMBER OF FE FACULTY AT THE COLLEGE OF NURSING, UNIVERSITY OF MASSACHUSETTS, BOSTON. DR. PALMERERBS WAS A POST DOCTORAL RESEARCH FELLOW AT THE CENTER FOR PSYCHIATRIC REHABILITATION WHEN THIS RESEARCH PROJECT WAS CONDUCTED.

\begin{abstract}
A longitudinal study presents the outcomes for participants in a psychiatric rehabilitation program for young adults. Five to nine years after the baseline and end of intervention, participants showed a maintenance of initial gains in vocational and educational status, self-esteem scores, and bospitalization rates. Additional data on work outcomes and quality of life are presented.
\end{abstract}

W atric rehabil ment and other outcomes have been documented (Bond, Dincin, Setze, \& Witherridge, 1984; Bond, Drake, Mueser, \& Becker, 1997; Lehman, 1995; National Institute on Disability and Rehabilitation Research, 1992), there are few studies that have examined the long-range outcomes associated with these interventions. Such studies have been advocated (Bond \& McDonel, 1991; National Institute of Mental Health, 1991) and are becoming more urgent in the climate of managed care. Data on the long-term effectiveness of psychiatric rehabilitation are necessary for advocating for inclusion of psychiatric rehabilitation into managed care funded services (Hughes, 1995;
McGuirk, Frank, Sanchez, \& Evants, 1994). Longitudinal data on the vocational outcomes and recovery for this population are emerging (Rogers, Anthony, Toole, \& Brown, 1991; Desisto, Harding, McCormick, Ashikaga, \& Brooks, 1995; Harding, Brooks, Ashikaga, Strauss, \& Breier, 1987; Rogers, Anthony, Toole, \& Brown, 1991). This study contributes to the developing picture of the long-range outcomes of disability and rehabilitation by providing 5-year follow-up data for a group of young adults who participated in a vocationally oriented rehabilitation program conducted by the Center for Psychiatric Rehabilitation. Longitudinal outcomes for work, education, hospitalization rates, and self-esteem are described below. Additional data on work and quality of life are presented.

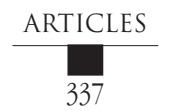




\section{Previous Study}

Between 1985 and 1989, 50 young adults with psychiatric disabilities participated in a study investigating the effects of a career education program (CEP) based on the Choose-Get-Keep approach to Psychiatric Rehabilitation (Danley, Sciarappa, \& MacDonaldWilson, 1992). The results of this intervention were previously published (Unger, Anthony, Sciarappa, \& Rogers, 1991). In the original study, a longitudinal, repeated-measures research design was used to evaluate the effect of participation in a career educational program on vocational and educational outcomes. All participants were required to be between ages 18 and 35; to possess average or higher intelligence, and to be able to attend and utilize a classroom-based program. In addition, each had experienced a severe disability due to mental illness that had resulted in impaired role functioning.

The intervention was a didactic application of the Psychiatric Vocational Rehabilitation approach (Anthony, Cohen, \& Danley, 1988). This intervention combined small group instruction in career development accompanied with individualized, supportive psychiatric rehabilitation counseling sessions. The intervention was designed to help participants to define a career goal and to develop and actualize a career plan. Structured classroom activities helped participants to choose an occupation that fitted their strengths and preferences and to identify and sequence the series of vocational environments (school and work) that would provide them with the experience they needed to enter a job of choice. Once the first environment was identified, the participant worked with a placement specialist to get access to and acceptance as a student or worker in a specific vocational setting. A detailed manual for this intervention is available (Danley, Hutchinson, \& Restrepo-Toro, 1998).
As reported earlier (Unger et. al., 1991), results of testing for proportional differences between baseline and end-point of intervention data showed that among 44 subjects for whom there were complete data, there was a significant increase in the percentage of students who became competitively employed (either part-time or full-time). There was also a significant increase in educational status among students. When the achievement of either an educational or vocational status was examined, there was a significant positive difference between baseline and end-point data. Analysis of available hospitalization data for a subset of 34 of the subjects showed a significant decrease in the number of hospitalizations that occurred during the first year of the intervention as compared to hospitalizations in the year before the intervention. Finally, using the Rosenberg self-esteem scale (Rosenberg, 1965), a paired samples $t$ test showed a significant increase in mean self-esteem scores from baseline to end -point $(N=43)$. This scale is composed of 10 items that have Likert scaling response options of one through four.

The follow-up study reported on here posed the following question: how did the educational/vocational status, hospitalization rates, and self-esteem scores for this same group of students fare from 5 to 9 years post baseline and endpoint of the intervention?

\section{METHOD}

An attempt was made to contact the same 50 students who originally participated in the program. Some students had maintained contact with the Center for Psychiatric Rehabilitation after the intervention through various means. The majority were contacted by referring to earlier address files and listings of friends and family members who might know their whereabouts. In addition, extensive efforts were also made to locate and contact a group of students who did not receive the intervention but who were wait-listed at the time of services and could serve as a comparison group to the intervention students.

Once a current address or telephone number was ascertained, students were contacted by phone and mail and were requested to complete data collection forms. Two group sessions were also held for data collection. Most respondents came independently to the Center for Psychiatric Rehabilitation to complete the forms, and several did so by telephone or mail. Each respondent received a $\$ 25$ payment for participating in the data collection.

Data was collected from 1992 through 1994. The follow-up instruments consisted of the same Rosenberg self-esteem scale (Rosenberg, 1965) and a set of questions on educational/vocational status and demographics that were drawn from the original data collection forms. For some respondents who were unwilling to complete the entire set of instruments, we obtained key information on educational and vocational status. In addition, a quality of life interview (Lehman, 1988) was administered to the follow-up group.

\section{RESULTS}

\section{Sample}

Of the original 50 students, we obtained data on $84 \%$ of the subjects. Thirty-six people completed the instruments, and 6 completed key information. Two persons refused to participate, and six were lost to followup. Locating and contacting the group of wait-listed students proved to be nearly impossible despite numerous and varied attempts, and so sufficient 
data are not available for this group. Table 1 presents demographic and clinical data for three groups: the original 50-member career education program group (CEP), the follow-up group of 36 (CEPII), and a comparison group of a national sample of community support clients surveyed in 1984 (Mulkern \& Manderscheid, 1989). Statistical tests showed little differences between the intervention group and the follow-up sample, except for self-reported diagnosis (greater follow-up members reported "other" diagnostic categories) and education (the follow-up sample had a greater number of people with posthigh school education-a likely result of the intervention itself). As compared with a national group of psychiatric clients, the original intervention group differed in expected ways, given the nature of selection criteria, that is they were younger, and better educated, with a greater percentage reporting affective disorders rather than schizophrenia. A greater percentage of the intervention group had also been previously hospitalized.

\section{Outcomes for Vocational and Educational Status}

To conduct analyses, as much data were preserved as possible. All missing data for the follow-up group were coded as having no work or educational status, providing a conservative estimation of outcomes. Using the McNemar test for difference in proportions (Siegal \& Catellan, 1988), a significant difference was maintained between the proportion of students who reported being currently employed at baseline data $(n$ $=7)$ and those who were working at the time of follow-up data collection ( $n$ $=20, p<.005, N=49)$. This difference was not apparent when testing between data collected at the end-point of the intervention and at follow-up $(p=.79$, $N=43$ ). These findings were repeated when analyzing differences between those who were either working, or in

\section{Table 1-Demographic and Clinical Characteristics of Young Adults with Severe Psychiatric Disabilities in the Career Education Program (CEP), in the Follow-up Study (CEPII), and in a National Comparison Group, in Percentages.}

\begin{tabular}{|c|c|c|c|}
\hline VARIABLE & $\begin{array}{c}\text { CEP } \\
(N=52)\end{array}$ & $\begin{array}{c}\text { CEPII } \\
(N=36)\end{array}$ & $\begin{array}{l}\text { COMMUNITY } \\
\text { SUPPORT } \\
(N=\mathbf{1 , 0 5 3 )}\end{array}$ \\
\hline \multicolumn{4}{|l|}{ Education $^{1}$} \\
\hline Less than high school & 2 & 0 & 46 \\
\hline High school diploma & 15 & 3 & 30 \\
\hline Post high school & 83 & 97 & 23 \\
\hline \multicolumn{4}{|l|}{ Gender } \\
\hline Male & 60 & 61 & 51 \\
\hline Female & 40 & 39 & 49 \\
\hline \multicolumn{4}{|l|}{ Race } \\
\hline White & 86 & 83 & 82 \\
\hline Black & 10 & 8 & 11 \\
\hline Other & 4 & 8 & 7 \\
\hline \multicolumn{4}{|l|}{ Marital Status $^{2}$} \\
\hline Married or living with mate & 6 & 8 & 14 \\
\hline Never married & 84 & 83 & 53 \\
\hline Other (divorced, widowed) & 10 & 8 & 33 \\
\hline \multicolumn{4}{|l|}{ Diagnostic Category ${ }^{3}$} \\
\hline Schizophrenia & 39 & 25 & 59 \\
\hline Affective disorder & 44 & 39 & 24 \\
\hline Other or missing & 17 & 36 & 19 \\
\hline \multicolumn{4}{|l|}{ Ever Hospitalized $^{4}$} \\
\hline Yes & 98 & 97 & 91 \\
\hline No & 2 & 3 & 9 \\
\hline \multicolumn{4}{|l|}{ On Psychotropic Medication } \\
\hline Yes & 92 & 92 & 87 \\
\hline No & 8 & 8 & 13 \\
\hline \multicolumn{4}{|c|}{$\begin{array}{l}{ }^{1} X^{2}=10.45, d f=2, p<.01 \text {, CEP subjects and community support group } \\
{ }^{2} X^{2}=22.51, d f=2, p<.001 \text {, CEP subjects and community support group } \\
{ }^{3} X^{2}=10.06, d f=2, p<.01 \text {, CEP subjects and community support group } \\
{ }^{4} X^{2}=4.71, d f=1, p<.05, \text { CEP subjects and community support group }\end{array}$} \\
\hline
\end{tabular}

school, or a training program. A significant difference was found between those either working or in school from baseline $(n=10)$ to follow-up $(n=28$, $p<.005, N=49)$ but this difference was not apparent when examining data between end-point and follow-up. Similarly, gains in educational or training status were observed between baseline data ( 3 in school) and at follow-up (10 in school, $p<.005, N=50$ ).

However, there was a nearly significant decrease in the proportion of students who were in school or in a training pro- gram from the end-point of intervention $(n=26)$ to the time of follow-up $(n=10, p=.065, N=50)$.

\section{Self-Esteem}

As measured by the Rosenberg self-esteem scale, mean self-esteem scores were compared for 35 students for whom data were available between baseline (mean $=2.52)$ and follow-up (mean $=2.80)$, and a significant difference was found in the positive direction $(t=2.71, d f=34, p=.01)$. Again, this difference was not apparent when ex- 
amining data between the end-point of intervention (mean $=2.59)$ and at follow-up for 32 students (mean $=2.76, t$ $=1.33, d f=31, p=.19$ ).

\section{Hospitalization Rates}

Out of the 34 students for whom original hospitalization data were available, 29 provided follow-up data. For these 29 students, there was no significant change in hospitalization rates between the end -point of intervention and at follow-up, when using the Wilcoxon Matched-Pairs Signed Ranks test. However, there was a trend toward increased hospitalizations $(z=-1.68, p=$ $.092)$ at the time of follow-up.

Comparing data from the end -point of intervention to the follow-up year, there were 19 ties, 8 people had increased hospitalizations, and 2 people had decreased hospitalizations. In terms of admissions, 5 people had one or more hospital admissions during the year ending the intervention and 24 people had no admissions; while during the follow-up year, 11 people had one or more admissions and 18 had none. Difficulties in reconstructing data prevented testing the differences in hospitalization rates from the year before intervention to the time of follow-up.

\section{Quality of Life}

Using the Quality of Life Interview developed by Lehman (1988), self-reported perceived satisfaction scores were averaged for the 36 follow-up participants in six life domains. The scores were based on a 7-point scale ranging from 1 (terrible) to 7 (delighted), with a score of 4 being "mixed," about equally satisfied and dissatisfied. Results were as follows: living situation $(x=4.74$, $S D=1.37)$; leisure activities $(x=4.39$, $S D=1.07)$; family relations $(x=4.59$, $S D=1.49)$; social relations $(x=4.60$, $S D=1.14)$; finances $(x=3.45, S D=$ $1.54)$; and personal safety $(x=4.46$, $S D=1.63)$. These data were compared with normative data provided by Lehman for people with diagnosis of se- vere depression (the majority of this sample reported having affective disorders). No statistically significant differences were found between the samples in scores using a $t$-test for each domain.

For the 36 people who completed the Quality of Life Interview, the following vocational profile emerges. Twenty-one people reported working in the past year. Seven people had sporadic work in service-related positions. Five people held positions in health and human services. Retail positions accounted for another three people; two people were in clerical positions, and one was in a technical position. Three other positions were not described. An additional three people were employed in sheltered workshops. On average, those employed worked 22 hours per week, earning on average $\$ 158$ /week $(n=$ 18). Their satisfaction with the job scored a mean 4.6 (on the 1-10 scale), with less satisfaction for the number of hours worked (3.9) and for the amount of pay (3.5). Twenty-two people reported receiving SSDI benefits, and 19 people also received rent supplements.

\section{Discussion}

Overall, the findings of the follow-up show considerable evidence for the enduring positive effects of the CEP program. In particular, initial gains in vocational status, self-esteem scores, and a reduction in hospitalization rates were maintained as many as 9 years later. An exception to this was educational status where there were fewer numbers of students still enrolled in school at follow-up a number of years later. This is not an unexpected finding when one considers the natural occurrence of young adults completing their education after several years and then moving to employment. The trend toward increased hospitalization suggests that this is the least stable effect of the intervention, though people were succeeding in working even when hospitalization rates were somewhat increased. Finally, we found that despite higher proportions of people working, the perceived quality of life was no different from that of a comparison group with similar diagnoses.

There are several weaknesses in this study, which suggest that findings should be interpreted with caution. The absence of a control group requires one to consider whether these gains might have been made by a similar group of students irrespective of the intervention. Also, the reduced sample at follow-up may suggest some bias among those who were locatable and willing to respond to the survey. However, the percent of original participants who were in the follow-up group (84\%) is still high, promoting confidence in the findings. When one considers the longterm effect of the intervention, one must also take into account the likely effect of intermittent informal involvement in Center services and projects by many of the original participants. Finally, these outcomes may only be generalizeable to a like young adult population with significant psychiatric histories and a completed high school education.

In order to replicate the evidence for long-term positive outcomes of psychiatric vocational rehabilitation interventions, there is a clear need for additional longitudinal studies of this nature, particularly for ones that succeed in including a control group. The need for this kind of data in today's climate of managed care services is even more pressing. Our vexing problems in locating and gaining the participation of a wait-listed student body as many as 10 years after the fact has been enlightening. A prospective and proactive view must be taken at the outset of research projects to secure the cooperation of participants many years later. Building 
in a longitudinal component, or at least the possibility of one, may be done by acquiring permission from participants, at the start of a program, to maintain contact with them after program conclusion. This can be done quite cheaply with semi-annual post cards to track changes of address. Such foresight will pay handsome dividends in the event that a longitudinal study is undertaken. Moreover, institutional review boards are increasingly requiring that permission to contact participants for followup studies must have been spelled out in the original informed consent process.

\section{COnClusions}

The original intervention was designed as a response to the need articulated by young adults with severe psychiatric disability for an age-appropriate vocational rehabilitation program. The program content, location, and process were selected to address the expressed preferences of this group for an alternative to existing day treatment and rehabilitation options. The psychiatric rehabilitation practitioners who delivered the intervention were clinically skilled and vocationally knowledgeable. The results indicate that participation in this program had both immediate and long-range personal and vocational benefits. This age group is still uniquely underserved by existing mental health and rehabilitation systems and underemployed in American society.

Programs such as the Career Education Program may provide an attractive and effective alternative for assisting young adults with psychiatric disabilities to reclaim productive and preferred vocational roles.

\section{REFERENCES}

Anthony, W. A., Cohen, M. R., \& Danley, K. S. (1988). The Psychiatric Rehabilitation Approach as applied to vocational rehabilitation. In J. A. Ciardiello \& M. D. Bell (Eds.), Vocational rebabilitation of persons with prolonged psychiatric disorders (pp. 59-80). Baltimore: John Hopkins University Press.

Bond, G., Dincin, J., Setze, P., \& Witherridge, T. (1984). The effectiveness of psychiatric rehabilitation: A summary of research at Thresholds. Psychosocial Rebabilitation Journal, 7(4), 6-22.

Bond, G. R., Drake, R. E., Mueser, K. T., \& Becker, D. R. (1997). An update on supported employment for people with severe mental illness. Psychiatric Services, 48, 335-346.

Bond, G. R. and McDonel, E. C. (1991). Vocational rehabilitation outcomes for persons with psychiatric disabilities: An update. Journal of Vocational Rebabilitation. 1(3), 9-20.

Danley, K. S., Hutchinson, D., \& RestropoToro, M. (1998). Career planning curriculum for people with psychiatric disabilities: Instructor's Guide. Boston: Center for Psychiatric Rehabilitation, Boston University.

Danley, K. S., Sciarappa, K., \& MacDonaldWilson, K. (1992). Choose-Get-Keep: A psychiatric rehabilitation approach to supported employment. New Directions in Mental Health Services, 53, 87-96.

DeSisto, M. J., Harding, C. M., McCormick, R. J., Ashikaga, T., Brooks, G. W. (1995). The Maine-Vermont three decade studies of serious mental illness: Longitudinal course comparisons. British Journal of Psychiatry, 167, 338-342.

Harding, C. M., Brooks, G. W., Ashikaga, T., Strauss, J. S., Breier, A. (1987). The Vermont longitudinal study: II. Longterm outcome of subjects who retrospectively met DSM-III criteria for schizophrenia. American Journal of Psychiatry, 144(6), 727-735.

Hughes, R. (1995). The future of psychosocial rehabilitation under managed care. Boston University, Center for Psychiatric Rehabilitation. Community Support Network News, 10(4), 3-4.
Lehman, A. F. (1988). A quality of life interview for the chronically mentally ill. Evaluation and Program Planning, 11, 51-62.

Lehman, A. F. (1995). Vocational rehabilitation in schizophrenia. Schizophrenia Bulletin, 21(4), 645-656.

McGuirk, F., Frank, D., Sanchez, A. \& Evants, D. (Eds.) (1994). Outcomes issues in a managed care environment. Boulder, CO: Western Interstate Commission for Higher Education.

Mulkern, V. M., \& Manderschied, R. W. (1989). Characteristics of community support program clients in 1980 and 1984. Hospital and Community Psychiatry, 40. 165-172.

National Institute of Mental Health (1991). National Advisory Mental Health Council. Caring for people with severe mental disorders: A national plan for research to improve services, [DHHS Pub. No. (ADM) 91-1762]. Washington, DC: Superintendent of Documents, U.S. Government Printing Office.

National Institute on Disability and Rehabilitation Research. (1992). Consensus statement. Strategies to secure and maintain employment for people with long-term mental illness, 1(3), 1-38. Washington, DC: U.S. Dept. of Education.

Rogers, E. S., Anthony, W. A., Toole, J., Brown, M. A. (1991). Vocational outcomes following psychosocial rehabilitation: A longitudinal study of three programs. Journal of Vocational Rebabilitation, 1(3), 21-29.

Rosenberg, M. (1965). Society and the adolescent self-image. Princeton, $\mathrm{NJ}$ : Princeton University Press.

Siegal, S. E., \& Catellan, N. J. (1988). Nonparametric statistics for the behavioral sciences (2nd ed.). New York: McGraw-Hill.

Unger, K. V., Anthony, W. A., Sciarappa, K., \& Rogers, E. S. (1991). A supported education program for young adults with long-term mental illness. Hospital and Community Psychiatry, 42, 838-842. 